\title{
Nötrozofik Küme Temelli Difüzyon Metodu Kullanılarak Görüntülerdeki Örtüşme Problemini Azaltma
}

\author{
Kazım Hanbay $^{1 *}$ \\ ${ }^{1}$ Bingöl Üniversitesi, Mühendislik ve Mimarlık Fakültesi, Bilgisayar Mühendisliği Bölümü, Bingöl, Türkiye (ORCID: 0000-0003-1374-1417)
}

(İlk Geliş Tarihi 26 Ocak 2020 ve Kabul Tarihi 9 Mart 2020)

(DOI: $10.31590 /$ ejosat.695191)

ATIF/REFERENCE: Hanbay, K. (2020). Nötrozofik Küme Temelli Difüzyon Metodu Kullanılarak Görüntülerdeki Örtüşme Problemini Azaltma. Avrupa Bilim ve Teknoloji Dergisi, (18), 505-514.

\begin{abstract}
$\ddot{O} \mathbf{z}$
Görüntü iyileştirme bilgisayar görmesi ve görüntü işleme uygulamalarında önemli bir konudur. Bu çalışmada kenar bölgelerindeki örtüşmeyi azaltmak için nötrozofik küme temelli yeni bir difüzyon metodu önerilmiştir. Ziou ve Horé'nin difüzyon denklemi temel alınarak, difüzyon denklemindeki gradyan ve eğrilik için yeni bir hesaplama metodolojisi önerilmiştir. Önerilen metotta örtüşme içeren görüntü nötrozofik kümeye dönüştürülür ve üç üyelik kümesi tarafından tanımlanır: doğruluk, belirsizlik ve yanlışlık. Daha sonra önerilen metot nötrozofik kümenin doğruluk ve yanlışlık üyeliklerini aktif olarak kullanır ve örtüşme etkilerini azaltır. Gradyan hesaplamasında önerilen metot orijinal giriş görüntüsü yerine nötrozofik doğruluk kümesini kullanır. Ayrıca eğrilik hesaplaması için nötrozofik yanlışlık kümesi kullanılmıştır. Nötrozofik üyelik kümeleri gürültüye karşı daha dayanıklı oldukları için, geleneksel difüzyon denklemlerinin dezavantajları gürültü açısından giderilmiştir. Nötrozofik kümeler gürültü bileşenlerini baskılayabilir ve böylece yumuşak gradyan ve eğrilik modelleri hesaplanabilir. Bu gradyan ve eğrilik bilgileri örtüşme içeren görüntüdeki hem kenar değişimlerini hem de örtüşme kalıntılarını yansıtır. Böylece Ziou ve Horé'nin denklemindeki ters yayınım işlemi etkili bir şekilde gerçekleştirilmiştir. Önerilen metot örtüşme kalıntılarını azaltırken nötrozofik küme vasıtasıyla kenar bölgelerinin detaylarını korumuştur. Deneysel sonuçlar önerilen metodun kenar bölgelerinde örtüşme problemlerini tespit edebildiğini göstermiştir. Yine önerilen difüzyon metodunun performansını değerlendirmek için Ortalama Karesel Hata (OKH) metriği kullanılmıştır. Sonuçlar aynı görüntüler üzerinde diğer metotların sonuçları ile karşılaştırılmıştır. Bu yeni metot görüntü işlemedeki uygulamalar için ön işlem adımı olarak kullanılabilecektir.
\end{abstract}

\section{Reducing Aliasing Problem in Images using Neutrosophic Set-Based Diffusion Method}

\begin{abstract}
Image enhancement is a significant topic in computer vision and image processing applications. In this paper, a new neutrosophic set based diffusion method is proposed to reduce aliasing on edge regions. Based on the diffusion equation of Ziou ve Horé, the new calculation methodology for gradient and curvature in the diffusion equation is presented. In the proposed method, aliased image is converted into the neutrosophic set and defined by three membership sets: truth, indeterminacy, and falsity. Then the proposed method actively uses the truth and falsity memberships of the neutrosophic set, and reduces aliasing artifacts. In the gradient calculation, the proposed method uses the neutrosophic truth instead of the original input image. Also, the neutrosophic falsity has been used to calculate the curvature calculation. Since the neutrosophic membership sets are more immune to noise, the disadvantage of traditional diffusion
\end{abstract}

\footnotetext{
* Sorumlu Yazar: Bingöl Üniversitesi, Mühendislik ve Mimarlık Fakültesi, Bilgisayar Mühendisliği Bölümü, Bingöl, Türkiye (ORCID: 0000-00031374-1417), khanbay@bingol.edu.tr
} 
equations has been resolved in terms of noise. The neutrosophic sets can suppress the noise components, and thus the smooth gradient and curvature models can be calculated. These gradient and curvature informations reflect both the edge changes and aliasing artifacts in aliased image. Thus inverse diffusivity process in the equation of Ziou ve Horé is performed efficiently. The proposed method reduces aliasing artifacts while preserving the details of edge regions through neutrosophic set. The experiment results show that the proposed method can detect the aliasing problems on edge regions. Also, Mean Square Error (MSE) metric is used to evaluate the proposed diffusion method's performance. The results are compared with results of other methods on the same images. This new method can be used as a pre-processing step for applications in image processing.

Keywords: Image enhancement, Neutrosophic set, Diffusion equation.

\section{Giriş}

Görüntü işlemede yüksek çözünürlüklü görüntüleme tekniklerinin ortaya çıkması görüntülerde var olan çözünürlük kaynaklı problemleri azaltmıştır. Görüntüleme cihazı kaynaklı özellikle bulanıklık, kontrast düzensizliği ve düşük çözünürlük gibi istenmeyen durumlar yüksek çözünürlüklü görüntüleme sayesinde herhangi bir iyileştirme işlemine gerek duyulmaksızın ortadan kaldırılabilmektedir. Ancak bazı durumlarda görüntüleme cihazından bağımsız olarak, elde edilen görüntüde bulanıklık, bilgi kaybı ve örtüşme gibi istenmeyen etkiler meydana gelebilmekledir. $\mathrm{Bu}$ durumlar görüntünün uygun görüntüleme sistemi ile kaydedilmemesinden, ortamın elverişsizliğinden veya görüntü üzerinde yapılan bazı ön işlemlerden kaynaklanmaktadır. Örneğin çok hızlı hareket eden bir nesne görüntülenirken çizgi tarama kamerası daha iyi görüntü alabilmektedir. Bunun yerine alan tarama kamerası kullanmak elde edilen görüntünün oldukça bulanık ve neredeyse hiçbir detayın görülemediği bir görüntü elde edilmesine yol açmaktadır. Bu gibi istenmeyen durumların önüne geçmek için uygun kamera seçimi ile birlikte aydınlatma tekniğine ve kamerada kullanılacak lens seçimine dikkat edilmelidir.

Görüntülerde bulunan ve görüntünün işlenip yorumlanmasına olumsuz etki eden birçok istenmeyen durum farklı iyileştirme yöntemleri ile kaldırılmaktadır (Yang vd., 2007; Ziou ve Horé, 2011). Ancak görüntülerde sıklıkla bulunabilen örtüşme (aliasing) problemi ile alakalı yapılan çalışma sayısı sınırlıdır. Örtüşme, görüntülerde daha çok kenar bölgelerinde basamak gibi görünen ve genellikle piksel sayısının az olmasından kaynaklanan bir durumdur. Basamak gibi görünen bu bölgelere örtüşme olarak adlandırılır. Dolayısıyla bu basamak gibi görünümler yumuşatılarak görüntünün kalitesi arttırılmalıdır. Şekil 1'de örtüşme içeren bazı görüntüler görülmektedir. Literatür incelendiğinde, özellikle medikal görüntülerdeki örtüşme problemi ile ilgili birçok çalışma yapıldığı görülmektedir (Yang vd., 2015; Zhao vd., 2019). Çünkü tıbbi görüntülemede kullanılan cihazların kapasitesi, görüntüleme alanının zorluğu, gürültü varlığı ve kontrast eksikliği nedenlerinden ötürü tıbbi görüntüler sıklıkla iyileştirme işlemlerine ihtiyaç duymaktadır. Bununla birlikte gri seviye ve renkli görüntülerde de örtüşme problemini gidermek için bazı yöntemler geliştirilmiştir. Bu yöntemlerdeki temel amaç görüntüdeki istenmeyen bileşenleri kaldırmak ve görüntüyü daha iyi analiz etmeye olanak sağlamaktır. Görüntülerdeki bulanıklık ve örtüşme problemlerini gidermek için yapılan bir çalışmada süper çözünürlük yapılanması metodu kullanılmıştır (Wang ve Qi, 2005). Örtüşme matrisi tanımlanarak bu matris ile düşük çözünürlüklü piksel bölgeleri tanımlanmış ve bu bölgelere yönelik iyileştirme işlemleri uygulanmıştır. Görüntülerdeki gürültüleri kaldırmak ve örtüşme problemini azaltmak için difüzyon işlemi kullanılmıştır (Perona ve Malik 1990). Böylece görüntüdeki farklı nesnelerin bölge sınırları korunurken, bölge içinde yumuşatma işlemi gerçekleştirilmiştir. Standart difüzyon denkleminden türetilen yeni bir algoritma ile kenar bölgelerindeki basamaklanma problemi azaltılmıştır (Ziou ve Horé, 2012). Kenar piksellerinin gradyan yönü boyunca bu piksellere difüzyon işlemi uygulanmıştır. Oldukça başarılı olan bu yöntem ile örtüşme problemi üzerinde daha iyi sonuçlar elde edilmiştir (Ziou ve Horé, 2012).
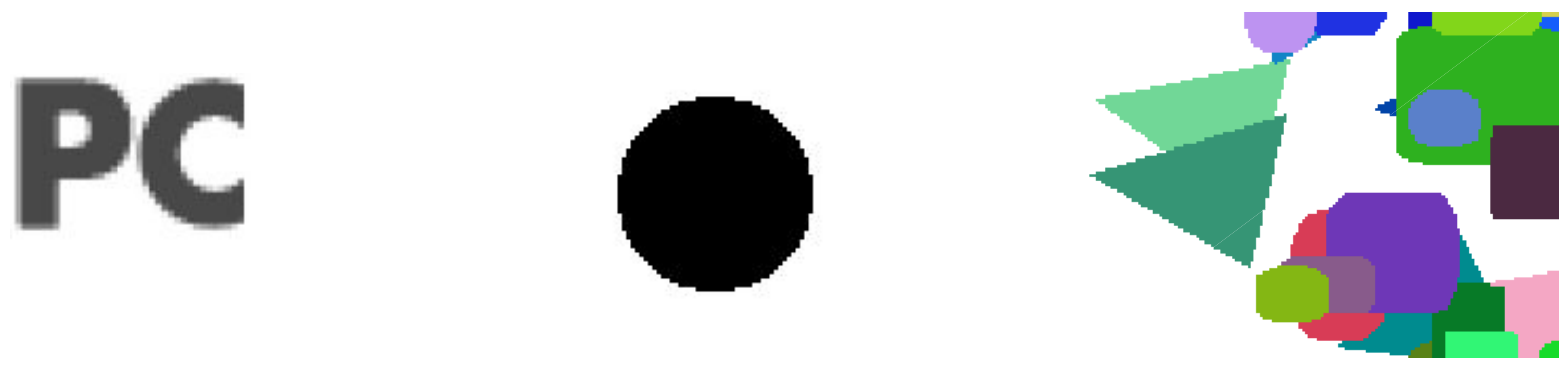

\section{Şekil 1. Örtüşme içeren görüntüler}

Geleneksel örtüşme problemi giderme yaklaşımları genellikle tüm görüntü üzerinde basit bir alçak geçiren filtre kullanmaktadırlar. Ancak bu yöntem örtüşme problemi ile birlikte aynı zamanda görüntüdeki kenar bilgilerini de zayıflatmaktadır. Bu durumu engellemek için dalgacık dönüşümü ve Fourier dönüşümü yöntemleri birlikte kullanılarak uyarlamalı bir görüntü iyileştirme yöntemi geliştirilmiştir (Chae vd., 2013). Geliştirilen yöntem ayrık dalgacık dönüşümü yönteminin LL alt bandını analiz ederek etkili sonuçlar elde etmiştir. Dalgacık dönüşümü temelli bir diğer yöntemde ise dalgacık dönüşümünün LH alt bandının HL alt bandına göre daha fazla örtüşme problemi içerdiği kabul edilerek LH bandı ele alınmış ve bu bant üzerinde örtüşme problemi giderilmeye çalışılmıştır (Gan ve Taubman, 2007). Diğer bir çalışmada bölgesel olmayan ortalama filtre kullanılarak tüm görüntü üzerinde filtreleme işlemi yapılmış ve yüksek frekans bileşeni olarak kabul edilen örtüşme bileşenleri ortadan kaldırılmıştır (Yang vd., 2011). Dalgacık dönüşümünde BC 52/60 ve BC 28/36 dalgacık filtre çiftleri kullanılarak filtre bankası oluşturulmuş ve böylece yüksek çözünürlüklü ve örtüşme içermeyen görüntüler elde edilmiştir (Winger, 1999). Fourier dönüşümü temelli bir başka yöntemde spektral filtre dizisi geliştirilerek örtüşme problemlerinde kullanılmıştır (Jia vd., 2016). Geliştirilen filtre dizisi sinüsoidal geniş bant spektral filtreler içermekte olup, örtüşme e-ISSN: 2148-2683 
problemine karşı etkili sonuçlar vermektedir. Güncel bir çalışmada ise mevcut Fourier temelli spektral filtre dizisi geliştirilerek multispektral filtre dizi geliştirilmiştir (Kawase vd., 2019). RGB görüntülemede kullanılan bu filtreler spektral filtrelerin farklı tiplerini içermektedir.

Örtüşme probleminin görüldüğü bir diğer uygulama ise sanal gerçeklik uygulamalarıdır. Sanal gerçeklik görüntüsü tek bir doku görüntüsü haline getirilerek görüntünün çıııntı (saliency) haritası oluşturulur (Sung ve Choi, 2017). Gauss filtreleme kullanılarak bir gauss görüntü piramidi inşa edilir. Piramit üzerinde her seviye üzerinde merkez piksel farklılıkları hesaplanarak elde edilen değerler yorumlanır ve örtüşme düzeyi hakkında bilgi sahibi olunur. Yönlü ağırlıklandırılmış interpolasyon yöntemi ile örtüşme bölgelerinin olmadığı görüntü bölgelerinden faydalanılarak görüntülerde iyileştirmeler yapılmıştır (Jiang vd., 2015). Yine görüntünün kırmızı ve mavi renk kanalları üzerinde interpolasyon yöntemi ile iyileştirmeler yapılarak iyileştirilmiş görüntü elde edilmiştir. İzotropik çekirdek fonksiyonlar kullanılarak geliştirilen iki boyutlu interpolasyon çekirdekleri ile görüntülerde kalite kaybına neden olan istenmeyen eklentiler zayıflatılmıştır (Kulberg ve Yakovleva, 2012). Radyal tabanlı fonksiyonlar yardımıyla geliştirilen yeni bir interpolasyon yöntemi ile görüntülerdeki kenar bilgileri korunarak iyileştirme işlemi yapılmıştır (Casciola vd., 2010). Bu yöntemde kenar bölgelerinin bilgileri interpolasyon işlemine dahil edilerek kenar yönelimleri korunmuştur. Kenar bilgisi difüzyonu yöntemi ile geliştirilen bir yöntemde endüstriyel uygulamalarda kullanılan bilgisayarlı laminografi görüntüleri üzerinde kenar bilgileri daha anlaşılır bir hale getirilmiştir (Zhao et al., 2018).

Görüntülerde başta örtüşme olmak üzere var olan problemleri gidermek için geliştirilen yöntemler incelendiğinde difüzyon ve interpolasyon temelli birçok yöntemin geliştirildiği görülmektedir (Ziou ve Horé, 2012). Yapılan çalışmalarda difüzyon denklemlerinin zayıf yönleri ve diğer uygulamalardaki eksiklikleri yorumlanarak denklemdeki eksikliği giderici çalışmalar önerilmiştir. Ayrıca yöntemler birlikte kullanılarak farklı yöntemlerin güçlü yönleri birleştirilmiştir. Böylece gri seviye, renkli ve çok bantlı farklı görüntüler üzerinde başarılı sonuçlara ulaşılmıştır. Yöntemlerin başarısı arttırılırken yöntemlerin zaman maliyeti, genelliği ve güvenilirliği gibi parametrelerde zaman zaman analiz edilmiştir.

$\mathrm{Bu}$ çalışmada görüntülerde bulunan örtüş̧e problemini azaltmak için nötrozofik küme teorisi ve difüzyon denklemini birlikte kullanan yeni bir yöntem geliştirilmiştir. Kullanılan difüzyon denklemi Perona ve Malik'in önermiş olduğu difüzyon denkleminin iyileştirilmiş hali olup, (Ziou ve Horé, 2012) tarafından örtüşme problemini azaltmak için geliştirilip kullanılmıştır. Yapılan kapsamlı literatür araştırmasından görüldüğü kadarıyla, nötrozofi yöntemi difüzyon işlemine ilk defa ve etkin bir şekilde entegre edilmiştir. Böylece iteratif difüzyon işleminin başarısı arttırılmış ve örtüşme problemine karşı iyi sonuçlar üretilmiştir. Ziou ve Horé, (2012), geliştirdikleri difüzyon denklemine doğrudan örtüşme içeren giriş görüntüsünü parametre olarak vermektedir. Yine eğrilik hesaplaması bu giriş görüntüsü üzerinde hesaplanarak iteratif bir şekilde difüzyon işlemi devam etmektedir. Ancak geliştirilen yöntemde giriş görüntüsünün nötrozofik küme bileşenlerinden doğruluk kümesi bilgisi difüzyon denklemine giriş parametresi olarak verilmiştir. Gradyan işlemi nötrozofik doğruluk kümesi kullanılarak hesaplanmıştır. Ayrıca giriş görüntüsü yerine nötrozofik yanlışlık kümesi kullanılarak piksellerin normal eğrilik bilgisi iteratif olarak hesaplanmıştır. Bu iki önemli fark önerilen yöntemin en temel yeniliği olarak görülmektedir. Nötrozofik doğruluk kümesinin difüzyon denkleminde yer alması sayesinde difüzyon denkleminin daha kararlı ve görüntü içeriğini kaybetmeden örtüşme bölgeleri iyileştirilmiştir. Bölüm 2'de nötrozofik küme teorisi ve kullanılan difüzyon denklemi kısaca incelenmiş̧ir. Bölüm 3 'te örtüşme problemini azaltmak için önerilen nötrozofik terimli difüzyon modelinin gradyan ve normal eğrilik hesaplamaları tanıtılmıştır. Bölüm 4'te bazı deneysel sonuçlara ve bu sonuçlara ilişkin yorumlara yer verilmiştir. Bölüm 5'te ise bazı öneri ve sonuçlara değinilmiştir.

\section{Materyal ve Metot}

\subsection{Nötrozofik Küme ve Nötrozofik Görüntü}

Florentin Smarandache tarafından geliştirilen nötrozofik küme (NS), felsefenin bir dalı ve mantı̆̆ın bir genellemesi olup kökeni, doğayı ve nötralitenin kapsamını inceleyen bir alandır (Smarandache ve Florentin, 2003). Nötrozofi teorisine göre her olay sadece doğruluk derecesi ile değil, aynı zamanda yanlışlık derecesi ile birlikte bir diğerinden bağımsız şekilde değerlendirilerek belirsizlik derecesine de sahiptir. Nötrozofi teorisi, herhangi bir (A) önermesini, olayını, veya niceliğini onun karşıtı (Anti-A) ve onu nötralize eden (Neut-A) ile birlikte inceler. Burada (Neut-A), ne (A) ne de (Anti-A)'dır. Bu teoreme göre doğadaki her (A) olayı, (Anti-A) ve (Neut-A) ile dengelenir. Nötrozofik dizide belirsizlik doğruluk derecesi, belirsizlik derecesi ve yanlışlık derecesi ile ölçülebilir. Bu kabul birçok uygulamada çok önemlidir. Çünkü herhangi bir önerme veya olayın sadece doğru veya yanlış olarak sınıflandıralamayacağ 1 bazı uygulamalarda bu teori esnek karar imkanı sunmaktadır (Smarandache vd., 2019).

Eğer $\mathrm{U}$ evrensel kümesi NS A kümesini içerirse, A kümesi içerisindeki bir x elemanı, $t$ 'nin $T$ içinde, $i$ 'nin $I$ içinde ve $f$ 'nin $F$ içinde değiş̧kenlik gösterdiği $x(t, i, f)$ olarak gösterilebilir. Bu $x(t, i, f)$ elemanı, şu şekilde $A$ kümesine ait olur: Bu eleman $\% t$ doğru, $\% i$ belirsiz, $\% f$ yanlıştır ( $t$ elemanı $T$ kümesi içinde, $i$ elemanı $I$ kümesi içinde ve $f$ elemanı $F$ kümesi içinde çeşitlilik gösterir). Sonuç olarak bir önermenin veya olayın üyelik fonksiyonu $T, I$ ve $F$ üyelik kümelerinde değerlendirilir (Mohan vd., 2013).

Bir görüntü $P_{N S} T, I$ ve $F$ olmak üzere üç nötrozofik üyelik kümesi tarafından karakterize edilir. Görüntüdeki bir $P(i, j)$ pikseli nötrozofik alanda $P(T, I, F)$ olarak tanımlanır. $P(T, I, F)$ pikseli nötrozofik piksel parlaklığı kümesi içerisinde $\% t$ doğru, \%i belirsiz ve $\% f$ yanlıştır. Görüntü pikseli $P(i, j)$ nötrozofik bölgeye dönüştürülerek $P_{N S}(i, j)=\{T(i, j), I(i, j), F(i, j)\}$ şeklinde ifade edilir. Burada $T(i, j), I(i, j)$ ve $F(i, j)$ nötrozofik üyelik fonksiyonları olup sırasıyla doğruluk, belirsizlik ve yanlışlık kümelerini ifade etmektedirler. Bu fonksiyonlar aşağıdaki gibi tanımlanırlar (Smarandache ve Florentin, 2003): 
$T(i, j)=\frac{\bar{g}(i, j)-\bar{g}_{\text {min }}}{\bar{g}_{\max }-\bar{g}_{\text {min }}}$

$\bar{g}(i, j)=\frac{1}{w \times w} \sum_{m=i-w / 2}^{i+w / 2} \sum_{n=j-w / 2}^{j+w / 2} g(m, n)$

$I(i, j)=\frac{\delta(i, j)-\delta_{\min }}{\delta_{\max }-\delta_{\min }}$

$\delta(i, j)=a b s(g(i, j)-\bar{g}(i, j))$

$F(i, j)=1-T(i, j)$

$g(i, j)$ sembolü $(i, j)$ pikselinin yoğunluk değerini gösterirken, $\bar{g}(i, j)$ sembolü $g(i, j)$ değerinin bölgesel ortalama değerini göstermektedir. $\delta(i, j)$ sembolü ise, $g(i, j)$ ve onun bölgesel ortalama değerini gösteren $\bar{g}(i, j)$ arasındaki farkın mutlak değeridir.

Bu çalışmada nötrozofik küme teorisi görüntü bölütleme veya kümeleme gibi işlemlerde kullanılmayacağı için, nötrozofik küme temelli bazı çalışmalarda kullanılan $\alpha$-ortalama, $\beta$-iyileştirme ve nötrozofik görüntü entropi hesaplaması gibi işlemlerin yapılmasına gerek duyulmamıştır. Yapılan bu işlemler belirsizlik kümesindeki elemanlarının dağılımı daha düzenli hale getirmek için kullanılır. Ayrıca bu işlemler ile $T$ ve $F$ kümesindeki elemanlarının $I$ kümesi ile olan ilişkileri düzenlenir. Önerilen örtüşme problemi azaltma yönteminde görüntü nötrozofik alana dönüştürülerek sadece $T$ ve $F$ kümeleri iteratif difüzyon işleminde gradyan ve normal eğrilik hesaplamak için kullanılmıştır. Bir görüntünün nötrozofik alana dönüştürülmesi ile elde edilen $T, F$ ve $I$ kümesi görüntüleri Şekil 2'de görülmektedir.

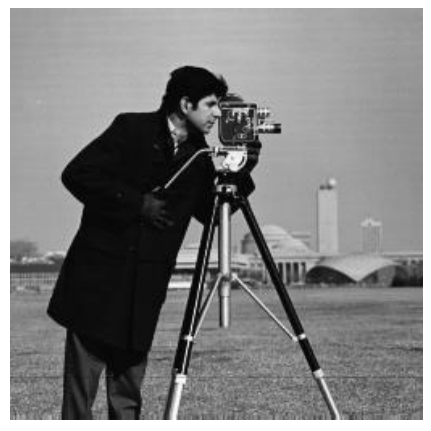

(a)

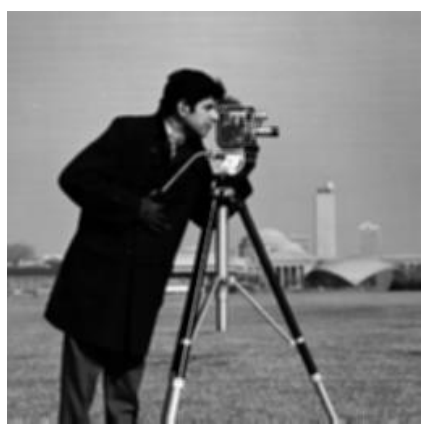

(b)

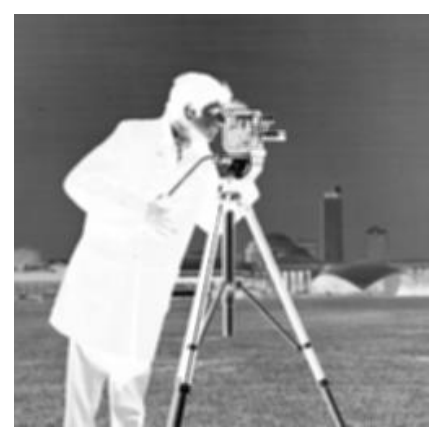

(c)

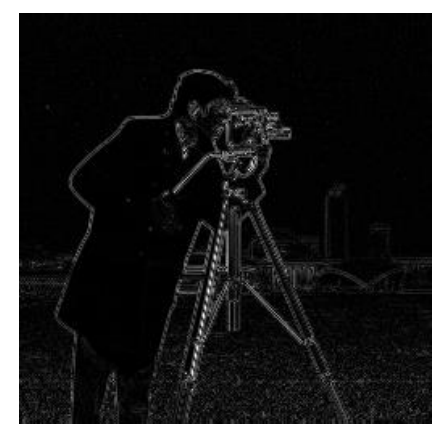

(d)

Şekil 2. Gri seviye bir görüntünün nötrozofik kümeye dönüştürülmesi ile elde edilen alt küme görüntüleri. (a) Orijinal gri seviye görüntü, (b) $T$ doğruluk kümesi görüntüsü, (c) F yanlışlık kümesi görüntüsü, (d) I belirsizlik kümesi görüntüsü

\subsection{Kısmi Diferansiyel Denklem Temelli Difüzyon}

Görüntülerde bulunan özellikle bulanıklık gibi problemlerin giderilmesinde difüzyon işlemi yaygın bir şekilde kullanılmaktadır (Khan vd., 2014; Li ve Meng, 2012; Nadernejad, vd., 2008). Yine gürültü giderme, kenar iyileştirme gibi uygulamalarda kullanılarak görüntünün bölütlenmesi ve kümelenmesi gibi işlemlerde kolaylık sağlar. Difüzyon işlemi genel olarak lineer ve lineer olmayan difüzyon olmak üzere ikiye ayrılmaktadır. Görüntü işleme uygulamalarında genellikle lineer olmayan difüzyon modelleri kullanılmaktadır (Khan vd., 2014). Lineer olmayan difüzyon modelleri de skaler ve tensör difüzyon modelleri olarak iki sınıfa ayrılmıştır. Özellikle tensör difüzyon modeli görüntü iyileştirmede kullanılarak istenmeyen bileşenler görüntülerden kaldırılmıştır. Görüntü işleme uygulamaları için ilk defa Perona ve Malik tarafindan lineer olmayan difüzyon yöntemi önerilmiştir (Perona ve Malik, 1990). Difüzyon işlemi analitik olarak difüzyon denklemi olarak bilinen aşağıdaki kısmi diferansiyel denklem kullanılarak tanımlanır (Khan vd., 2014; Ziou ve Horé, 2012):

$\left\{\begin{array}{l}\frac{\partial f(x, y, t)}{\partial t}=\operatorname{div}[\lambda(x, y, t) \nabla f(x, y, t)] \\ f(x, y, 0)=f_{0}(x, y)\end{array}\right.$ 
Burada $f(x, y, t)$ ve $\lambda(x, y, t)$ sirasıyla $(x, y)$ piksel konumunda ve $t$ zamanında difüzyon yoğunluğunu ve difüzyon katsayısını ifade etmektedirler. $\nabla$ gradyan operatörünü, div ise difüzyon operatörünü ifade etmektedir (Perona ve Malik, 1990). Denklem (6)'da $\lambda$ katsayısı sabit olmayıp $x, y$ ve $t$ değerlerine bağlı olarak değişmektedir. Bazı çalışmalarda $\lambda$ katsayısı aşağıdaki gibi ifade edilmiştir (Ziou ve Horé, 2012):

$$
\lambda(x, y, t)=\frac{1}{1+\left(\frac{\|\nabla f(x, y, t)\|}{\beta}\right)^{2}}
$$

Burada $\beta$ katsayısı difüzyon faktörünü kontrol etmektedir. $\lambda$ değeri gradyan değerine göre artıp azalmaktadır. Özellikle görüntünün kenar bölgelerinde $\lambda$ değeri azalırken, değişim içermeyen arka plan veya kenar olmayan bölgelerde $\lambda$ değeri artmaktadır. Böylece difüzyon işleminin iteratif olarak görüntünün gradyan değerine göre görüntü üzerinde işlem yaptığı anlaşılmaktadır.

Difüzyon denkleminin etkinliğini arttırmak için, literatürde yapılan bazı çalışmalar ile farklı yapılarda difüzyon denklemleri geliştirilmiştir (Abdallah ve Zineb, 2019; Jidesh ve George, 2012; Ziou ve Horé, 2012). Yapılan çalışmalar ile geleneksel difüzyon denkleminin güçlü gürültü varlığında kenar bölgelerinde sebep olduğu bilgi kaybı önlenmeye çalışılmıştır. Ayrıca difüzyon eşikleme parametresini belirlenmesi ve kontrol edilmesi yeni yöntemler ile daha kolay hale getirilmeye çalışılmıştır. Özellikle Gaussian gradyan modeli kullanılarak geliştirilen difüzyon yöntemleri bahsedilen zorluklara karşı etkin sonuçlar üretmiş̧tir (Liu vd., 2018).

Ziou ve Horé tarafindan geliştirilen ve Denklem 8 'de görülen güçlü difüzyon denklemi kullanılarak gri seviye ve renkli görüntülerdeki örtüşme problemi azaltılmıştır (Ziou ve Horé, 2012). Onlar Perona ve Malik tarafindan geliştirilen difüzyon denkleminin kenar çevrelerindeki örtüşme giderici etkinliğini güçlendirmek için yeni bir difüzyon denklemi geliştirmişlerdir. Burada not edilmesi gereken önemli bir husus şudur: Onlar geliştirdikleri yöntemde renkli görüntüleri öncelikle YUV renk uzayına dönüștürerek sadece Y bandı üzerinde difüzyon işlemi yapmışlardır. Bu noktada $\lambda$ katsayısının $Y$ bandı üzerinde ve özellikle gradyan değişiminin yüksek olduğu bölgelerde etkinliğini kontrol etmek için aşağıdaki denklem geliştirilmiştir:

$$
\left\{\begin{array}{l}
\frac{\partial f(x, y, t)}{\partial t}=[1-\lambda(x, y, t)] \kappa\|\nabla f(x, y, t)\| \\
f(x, y, 0)=f_{0}(x, y)
\end{array}\right.
$$

Burada $\kappa$ kenar boyunca normal eğriliği, $\nabla$ ise gradyan operatörünü göstermektedir. $t=0$ başlangıç zamanında $f=f_{0}$ dır. Denklem 8 'de verilen $\lambda$ yayınım işlemi Denklem 7'de verilen ifade kullanılarak hesaplanmaktadır. Denklem 8 'de görüldüğü gibi, yayınım işlemi $1-\lambda(x, y, t)$ şeklinde kullanılarak ters yayınım yapılmıştır. Buradaki amaç örtüşme içeren kenarlarda daha küçük yayınım değerleri elde edilmesini sağlamaktır. Böylece daha yüksek $\|\nabla f\|$ değeri elde edilerek kenar bölgelerinde daha fazla difüzyon etkisi oluşturulması amaçlanmıştır. Homojen görüntü bölgelerinde $1-\lambda(x, y, t)$ değeri 0'a yaklaşır (Ziou ve Horé, 2012). Bunun sonucu olarak Denklem 8 'de görüldüğü gibi $\kappa$ eğriliğinin etkisi azaltılır. Bu durumda örtüşme içermeyen homojen görüntü bölgelerinde difüzyon işleminin etkisi azaltılarak bilgi kaybının ve aşırı filtrelemenin önüne geçilebilir.

Örtüşme problemini gidermek için geliştirilen difüzyon denklemi gri seviye ve renkli görüntülerde başarılı sonuçlar vermekle birlikte bazı kısıtlılıklara sahiptir. Denklemde kullanılan eğrilik bilgisi geleneksel komşu piksel farkına dayalı gradyan hesaplaması ile elde edildiği için hesaplanan eğrilik bilgisinin ayırt ediciliği diğer türev hesaplama yöntemlerine göre daha zayıftır. Ayrıca eğrilik bilgisi doğrudan giriş görüntüsü kullanılarak hesaplanmaktadır. Giriş görüntüleri gürültü, bulanıklık ve kontrast eksikliği gibi problemler içerdiğinde, hesaplanan eğrilik bilgisinin ayırt ediciliği beklenen düzeyde olmamaktadır. Hâlbuki bu eğrilik bilgisi Denklem 8 ile birlikte difüzyon işleminde iteratif bir yaklaşım ile tüm görüntü pikselleri için hesaplanmaktadır. Tüm pikseller için ayrı ayrı hesaplanan eğrilik bilgisi $\kappa$ gradyan bilgisi $\|\nabla f\|$ ile her iterasyonda etkileşerek denklemin tümü üzerinde güçlü bir etkiye sahiptir. Bu noktada Denklem 8 üzerinde aktif bir şekilde kullanılan eğrilik bilgisinin ayırt ediciliğini ve belirleyici rolünü arttıracak çalışmalar ile örtüşme problemine farklı çözümler getirilebilir.

\section{3. Önerilen Nötrozofik Küme Temelli Difüzyon Yöntemi}

Bir önceki bölümde bahsedildiği gibi, difüzyon işleminde giriş görüntüsünün $\lambda$, gradyan, laplace ve eğrilik gibi hesaplamaların içinde aktif olarak kullanılması difüzyon işlemi üzerinde olumsuz etkilere yol açabilmektedir. Giriş görüntüsünde bulunabilen gürültü ve kontrast eksikliği gibi bazı istenmeyen bileşenler özellikle kenar ve köşe gibi bölgelerde aşırı veya eksik difüzyon işlemine yol açmaktadır. Ayrıca bir nesnenin iç bölgelerinde homojen bölgeler olabilmekle beraber, bu bölgelerde difüzyon yapılması ile aşırı yumuşatılmış bir görüntü oluşabilmektedir. Bunun sonucunda bilgi kaybı meydana gelip, sınıflandırma veya bölütleme gibi ileri işlemlerde başarı oranı düşmektedir. Bu noktada görüntüdeki örtüşme problemi kaldırılırken, görüntünün farklı bölgelerindeki ayırt edici öznitelik bilgilerinin korunması sağlanmalıdır. Aksi halde görüntüden anlamlı ve ayırt edici öznitelik bilgileri elde edilemeyerek sinıflandırıcının performansı zayıflatılacaktır. 
Bu çalışmada Denklem 8'de verilen difüzyon denkleminden yola çıkılarak, bu denklemin örtüşme azaltıcı etkisini arttırmak için nötrozofik doğruluk ve yanlışlık kümelerini aktif olarak kullanan yeni bir difüzyon yöntemi geliştirilmiştir. Önerilen yeni yöntemde nötrozofik kümeler şu şekilde kullanılmıştır:

İlk olarak $[1-\lambda(x, y, t)]$ şeklinde tanımlanan ters yayınım işleminde $\lambda(x, y, t)$ katsayısının hesaplanmasında giriş görüntüsü yerine nötrozofik doğruluk kümesi $T$ kullanılarak yatay ve dikey yönde gradyan bilgisi hesaplanır. Gri seviye görüntülerde, görüntü ilk olarak nötrozofik alana dönüştürülür. Daha sonra elde edilen nötrozofik doğruluk $T$ kümesi (görüntüsü) kullanılarak gradyan hesaplaması yapılır. Gradyan hesaplamasında Gaussian türev filtrelerinden faydalanılmıştır. Nötrozofik doğruluk kümesi $T$ kullanılarak yatay ve dikey yönde gradyan bilgisi aşağıdaki şekilde matematiksel olarak ifade edilir:

$\operatorname{grad} X=T^{*} G_{x}$

$\operatorname{grad} Y=T^{*} G_{y}$

Burada $G_{x}$ ve $G_{y}$ Gaussian fonksiyonunun birinci türevleri kullanılarak inşa edilen sirasıyla birinci mertebe yatay ve dikey türev filtrelerini göstermektedir. Gri görüntü üzerinde hesaplanan Nötrozofik $T$ kümesi ile bu filtreler evrişim işlemine tabi tutularak $T$ kümesinin yatay ve dikey gradyan bilgileri hesaplanmıştır. $\operatorname{gradX}$ ve $\operatorname{grad} Y$ kullanılarak gradyan büyüklüğü hesaplanmıştır. Elde edilen gradyan bilgisi Denklem 7 içerisinde kullanılarak $\lambda$ hesaplanır. Nötrozofik küme temelinde hesaplanan $\lambda$ bilgisi Denklem 8 'de görüldüğü gibi iteratif olarak difüzyon işleminde aktif olarak kullanılır. Renkli görüntülerde ise, renkli görüntü nötrozofik alana dönüştürüldükten sonra elde edilen renkli nötrozofik doğruluk kümesi $T$ YUV renk uzayına dönüştürülür. Daha sonra sadece Y bandı kullanılarak $\lambda$ bilgisi Denklem 7'de ki gibi hesaplanır. $T$ kümesi kullanılarak yapılan difüzyon işlemi sonrasında elde edilen iyileştirilmiş görüntü tekrar RGB uzayına dönüştürülür. Gri seviye ve renkli görüntüler için ters yayınım işleminde giriş görüntüsü yerine nötrozofik doğruluk kümesi $T$ kullanımı önerilen yeni yöntemin önemli farklılıklarından biridir.

Ziou ve Horé tarafindan önerilen yöntemin difüzyon denkleminde (Denklem 8) kullanılan bir diğer önemli terim eğrilik bilgisi $\kappa$ hesaplamasıdır (Ziou ve Horé, 2012). Eğrilik bilgisi her iterasyonda gri seviye giriş görüntüsünün tüm pikselleri üzerinde hesaplanmaktadır. Renkli görüntülerde ise görüntü YUV renk uzayına dönüştürülerek sadece Y bandı üzerinde eğrilik hesaplanmaktadır. Elde edilen $Y$ bandında giriş görüntüsünde bulunabilen gürülttï gibi bileşenler hesaplanan eğrilik bilgisinde bazı istenmeyen değişim bilgilerinin örtüşme problemi olarak algılanmasına neden olmaktadır. Bununla birlikte özellikle bazı görüntülerin homojen bölgelerinde bilgi kaybına ve aşırı yumuşatma işlemine neden olmaktadır. Bu nedenle önerilen yeni yöntemde Denklem 8'de kullanılan eğrilik bilgisinin $\kappa$ hesaplanmasında giriş görüntüsü yerine nötrozofik yanlışlık kümesi $F$ kullanılmıştır. Gri seviye görüntüler için nötrozofik kümede tanımlanan $F$ görüntüsü ile eğrilik hesaplaması yapılmıştır. Renkli görüntülerde ise görüntü nötrozofik kümede tanımlanarak elde edilen RGB renk uzayındaki $F$ görüntüsü YUV uzayına dönüştürülür. Sadece Y bandı üzerinde eğrilik hesaplaması yapılır. Bu bilgiler doğrultusunda eğrilik bilgisi $\kappa$ matematiksel olarak aşağıdaki gibi hesaplanmıştır:

$d_{x}=((F(x+1, y)-F(x-1, y)) / 2)$

$d_{y}=((F(x, y+1)-F(x, y-1)) / 2)$

$d_{x x}=(F(x+1, y)-2 F(x, y)+F(x-1, y))$

$d_{y y}=(F(x, y+1)-2 F(x, y)+F(x, y-1))$

$d_{x y}=((F(x+1, y+1)+F(x-1, y-1)-F(x+1, y-1)-F(x-1, y+1)) / 4)$

Yukarıdaki denklemlerde $F$ giriş görüntüsünün nötrozofik alana dönüştürülmesi ile elde edilen nötrozofik yanlışlık kümesini göstermektedir. $d_{x}$ ve $d_{y}$ nötrozofik yanlışlık kümesi $F$ 'nin yatay ve dikey yönlerdeki birinci türev bilgilerini gösterirken, $d_{x x}, d_{y y}$ ve $d_{x y}$ ise nötrozofik yanlışlık kümesi $F$ 'nin yatay, dikey ve diagonal yönlerdeki ikinci türev bilgilerini göstermektedir. Vurgulanması gereken temel nokta ise eğrilik hesaplamasında kullanılan bu türev bilgilerinin giriş görüntüsü yerine nötrozofik yanlışlık kümesi $F$ 'den elde edilmiş olmasıdır. Böylece nötrozofik yanlışlık kümesi kullanılarak eğrilik bilgisi $\kappa$ aşağıdaki gibi hesaplanır:

$\kappa=\frac{d_{x}^{2} d_{y y}-2 d_{x} d_{y} d_{x y}+d_{y}^{2} d_{x x}}{\left(d_{x}{ }^{2}+d_{y}{ }^{2}\right)^{3 / 2}}$

Önerilen nötrozofik küme temelli difüzyon denklemi $\lambda$ ve $\kappa$ bilgilerinin Denklem 8 'de kullanılmasına dayanmaktadır. Böylece giriş görüntüsünü temel alarak yapılan difüzyon temelli iyileştirme prosedürüne yeni bir bakış açısı kazandırılmışıı. Nötrozofik küme bileşenlerinin difüzyon işleminde kullanılması ile etkin gradyan ve normal eğrilik bilgisi hesaplamaları yapılmıştır. Böylece değişim bilgisinin yoğun olduğu örtüşme bölgelerinde gradyan ve eğrilik hesaplamalarının ayırt ediciliği arttırılırken, homojen bölgelerdeki bilgi kaybı ve aşırı filtreleme azaltılmıştır. Önerilen yöntemin akış diyagramı Şekil 3'te verilmiştir. 


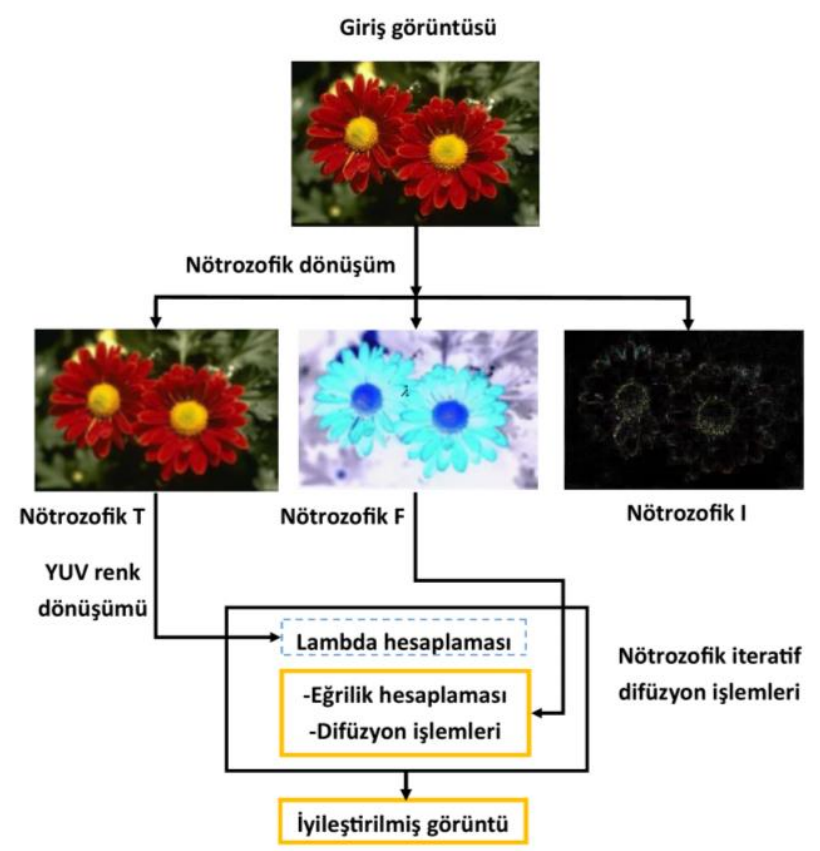

Şekil 3. Renkli görüntü için önerilen yöntemin temel işlem adımları

\section{Deneysel Sonuçlar ve Tartışma}

Geliştirilen nötrozofik küme temelli difüzyon yönteminin etkinliğini göstermek için bir dizi uygulama yapılmıştır. Geliştirilen yöntem literatürdeki iki farklı yöntem ile karşılaştırılmıştır. İlk yöntem Perona ve Malik tarafından geliştirilen ve orijinal difüzyon denklemini kullanan yöntemdir (Perona ve Malik, 1990). Diğer yöntem ise Ziou ve Horé tarafından orijinal difüzyon denkleminin kısmi diferansiyel denklem temelinde geliştirilmesi ile önerilmiş olan difüzyon yöntemidir (Ziou ve Horé, 2012). Kolaylık olması açısından Perona ve Malik tarafından geliştirilen yöntem P-M yöntemi, Ziou ve Horé tarafından yöntem ise Z-H yöntemi olarak anılacaktır. İlk olarak yöntemlerin gri seviye görüntü üzerindeki örtüşme giderici etkinlikleri analiz edilmiştir. Üç yöntem için difüzyon işlemi iterasyon sayısı 5 olarak sabitlenmiştir. P-M yöntemi için integrasyon sabiti 1/7, ayrık kısmi diferansiyel denklem çözümünde kullanılan katsayı (kappa) ise optimal sonucu verecek şekilde seçilmiştir. Z-H ve önerilen yöntem için filtre boyutları yatay ve dikey yön için 5, Gaussian türev için standart sapma değeri 1 olarak alınmıştır. Diğer bazı parametreler ise iki yöntem için aynı kullanılmıştır. Şekil 4'te örtüşme azaltma amaçlı geliştirilen yöntemlerin sonuçları görülmektedir. İlk satır elde edilen iyileştirilmiş görüntüleri, ikinci satır ise iyileştirilmiş görüntünün bir bölümünün büyültülmüş halidir. Böylece sonuçların özellikle görsel açıdan daha iyi yorumlanabilmesi sağlanmıştır. P-M yöntemi yüz ve boyun bölgesinde aşırı filtreleme yaptığı için özellikle ağız, burun ve göz bölgelerini tüm yüz bölgesine benzer bir şekilde üretmiştir. Özellikle bölütleme gibi uygulamalarda bu durum olumsuz sonuçlara yol açacaktır. Ayrıca saç kısımlarında diğer yöntemlere göre daha fazla örtüşme kalıntısı vardır. Z-H yöntemi P-M yöntemine göre daha iyi sonuçlar vermiştir. Önerilen nötrozofik küme temelli yöntem ise Z-H yöntemine göre kısmen daha iyi sonuçlar üretmiştir. Şekil 4'ten görüldüğü gibi, özellikle yüz bölgesindeki detaylar önerilen yöntem ile daha iyi korunmuştur. Ayrıca palto ve saç bitimi gibi alanlarda gürültü sayılabilecek piksel izleri daha azdır.

a

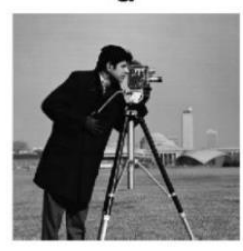

b

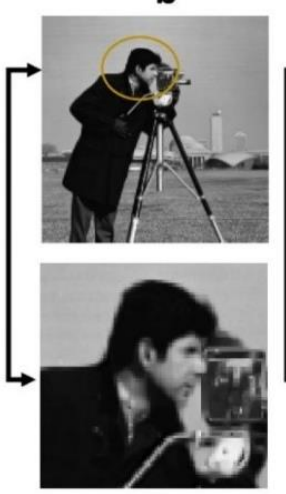

C

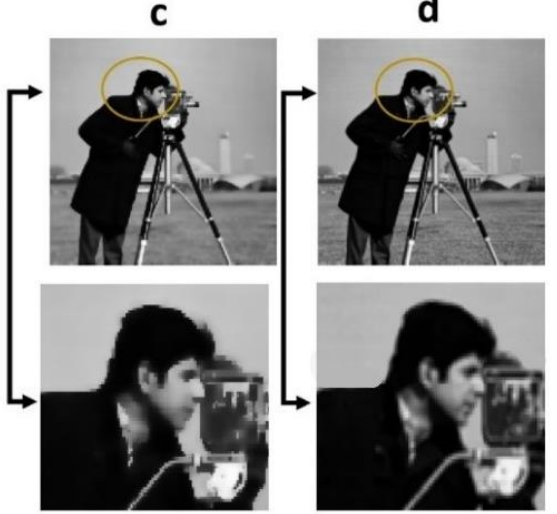

Şekil 4. Bazı örtüşme etkileri eklenen gri seviye görüntü ve yöntemlerin örtüşme giderici işlemleri sonucu elde edilen görüntüler. (a) örtüşme içeren orijinal görüntü, (b) Ziou ve Horé yönteminin sonuçları (c) Perona ve Malik yönteminin sonuçları, (d) önerilen yöntemin sonuçlart 
İkinci uygulamada renkli görüntü üzerinde önerilen yöntemin etkileri incelenmiştir. Görüntüye örtüşme etkileri eklenmiştir. Şekil 5 'te yöntemlerin sonuçları ile bazı bölgelerin sonuçlarının büyültülmüş görüntüleri verilmiştir. Z-H yöntemi görüntüde özellikle kenar bölgelerinde başarılı sonuçlar vermiştir. Örneğin şapka ve omuz bölgelerinde Z-H yöntemi ile örtüşme etkisi azaltılmıştır. Ancak sonuçlar görsel olarak yorumlandığında ise başka bir problem göze çarpmaktadır. Daha önce de bahsedildiği gibi, örtüşme etkileri azaltılırken görüntüdeki önemli bilgiler kaybedilmemelidir. Fakat Z-H yöntemi görüntünün geneli üzerinde aşırı filtreleme yaptı̆̆ için fazla yumuşatma yapılmasına neden olmuştur. Şekil 5-b'de görüldüğü gibi bu durum göz ve kaş bölgelerinde sınırların belirginliğinde azalmaya neden olmuştur. P-M yöntemi görüntü üzerinde fazla netlik yaparak keskinliğe yol açmıştır. Örtüşme etkisinin olduğu bölgelere yaptığı gradyan temelli filtrelemede görüntünün orijinal görüntüden farklı olarak histogram dağılımını da etkileyecek şekilde keskinlik belirtileri bırakmıştır. Bu durum görüntünün orijinal görüntü ile olan benzerliğini azaltmıştır. Yine zıtlık eksikliği içeren göz gibi bölgelerde kısmi olarak renk ve piksel kaybına yol açmıştır. Önerilen yöntem diğer iki yönteme göre görece olarak daha iyi sonuçlar üretmiştir. Özellikle Z-H yöntemi ile karşılaştırıldığında, göz bölgesinde daha iyi ve belirgin farkl1lıklar içermektedir. Z-H yöntemi iyileştirme yaparken sağ kaşın uzunluğunu ve göz çevresinin sınırlarını koruyamazken, nötrozofik küme temelli yöntem bu bölgeleri koruyabilmiştir. Nötrozofik $T$ kümesi ile hesaplanan gradyan ile görüntünün kenar bölgeleri korunurken, Nötrozofik $F$ kümesi ile de kenar bölgeleri boyunca arka plandan farklı ve gürülttüden az etkilenen eğrilik bilgisi hesaplanabilmiştir.

a
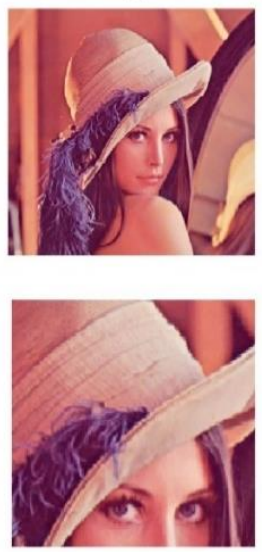

b
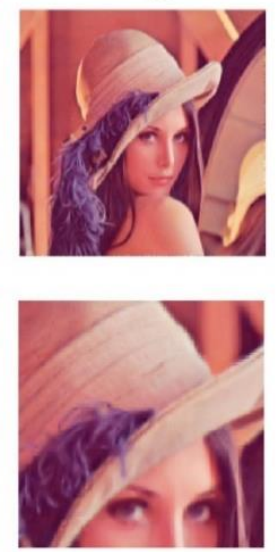

C
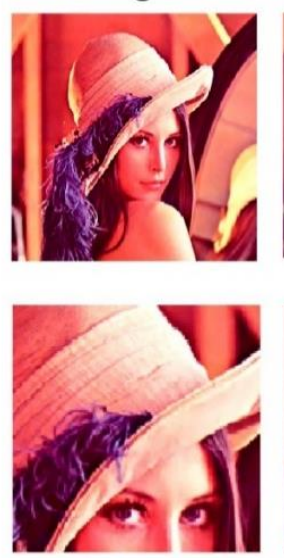

d
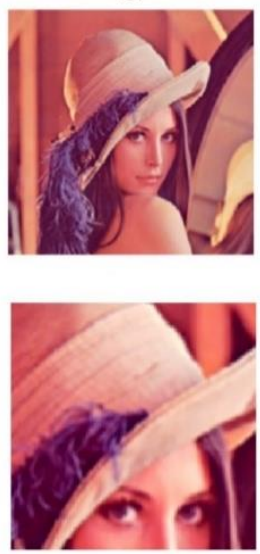

Şekil 5. Bazı örtüşme etkileri eklenen renkli görüntü ve yöntemlerin bu görüntü üzerindeki örtüşme giderici işlemler sonucu elde ettikleri görüntüler. (a) örtüşme içeren orijinal görüntü, (b) Ziou ve Horé yönteminin sonuçları (c) Perona ve Malik yönteminin sonuçları, (d) önerilen yöntemin sonuçları

Yapılan son uygulamada çizgi içeren bir görüntü kullanılmıştır. Şekil 6'da yöntemlerin sonuçları ile bazı bölgelerin sonuçlarının büyültülmüş görüntüleri verilmiştir. Kenar bölgelerdeki örtüşme etkisi Z-H yöntemi ile azaltılmıştır. İyileştirme yapılırken temel bilgilerin korunması açısından Z-H yöntemi bazı problemler içermektedir. Ancak bu yöntem diğer uygulamalarda olduğu gibi, iyileştirme yaparken kenar çizgilerinin özellikle bitiş kısımlarını arka plandan etkilenerek kısaltmıştır. Şekil 6-b'de ilk satırda bu durum görülebilir. Örneğin kaş ve kulak çizgileri orijinal görüntüye göre daha kısadır. Ayrıca tüm görüntü üzerinde bulanıklaşma etkisi bırakmıştır. P-M yöntemi ise kenar bölge sınırlarını korurken örtüşme gidermede yeteri kadar etkili olamamıştır. Kenar bölgelerinin iç kısımları korunurken, arka plana yakın dış sınırlarda örtüşme etkisi devam etmiştir. Önerilen yöntem diğer iki yönteme göre daha kabul edilebilir bir etkiye sahiptir. Özellikle kenar bölgelerinin sınırları tam olarak korunabilmiştir. Görüntünün örtüşme içermeyen bölgelerinde aşırı filtreleme yapmamıştır. Örtüşme bölgelerinde yumuşatma yaparak problemi diğer yöntemlere göre daha iyi çözmüştür.
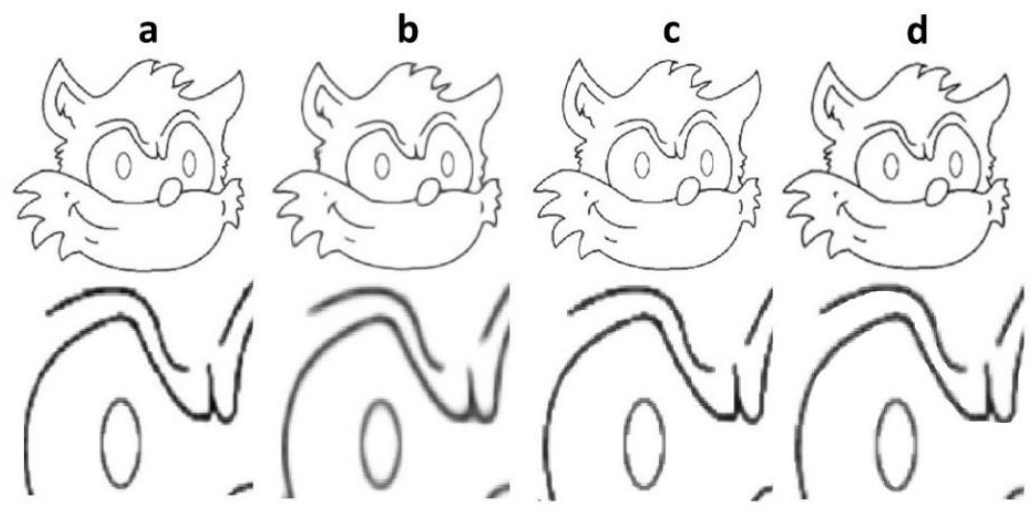

Şekil 6. Örtüşme etkileri eklenen görüntü ve yöntemlerin örtüşme giderici işlemler sonucu elde ettikleri görüntüler. (a) örtüşme içeren orijinal görüntü, (b) Ziou ve Horé yönteminin sonuçları (c) Perona ve Malik yönteminin sonuçları, (d) önerilen yöntemin sonuçlart 
Yöntemlerin örtüşme giderme başarıları görsel sonuçların yanı sıra, ayrıca Ortalama Karesel Hata (OKH) açısından da incelenmiştir. Tablo 1'de kenar noktalarındaki OKH değerleri verilmiştir. Kenar noktalarındaki OKH değerleri örtüşme içeren orijinal görüntü ve yöntemlerin elde ettikleri iyileştirilmiş görüntü ile karşılaştırılmıştır. Önerilen yöntem diğer yöntemlere göre daha küçük OKH değeri elde etmiştir. Önerilen yöntem hem kenar bilgilerini korumada hem de örtüşmeyi azaltmada etkin olduğu için daha iyi OKH değerlerine sahip olabilmiştir.

Tablo 1. Kenar piksellerde ortalama karesel hata (OKH) değerleri. ÖG:örtüşme içeren görüntü, Z-H: Ziou ve Horé yöntemi, P-M: Perona ve Malik yöntemi, NY: Önerilen nötrozofik yöntem

\begin{tabular}{l|c|c|c|c}
\hline Görüntü & ÖG & Z-H & P-M & NY \\
\hline Şekil 4 & 1493.34 & 1097.14 & 1261.57 & $\mathbf{1 0 2 7 . 3 4}$ \\
\hline Şekil 5 & 924.49 & 586.42 & 785.24 & $\mathbf{5 4 3 . 8 1}$ \\
\hline Şekil 6 & 986.82 & 728.31 & 824.38 & $\mathbf{7 1 3 . 2 7}$ \\
\hline
\end{tabular}

\section{Sonuç}

$\mathrm{Bu}$ çalışmada görüntülerdeki örtüşme problemini azaltmak için Ziou ve Horé tarafından geliştirilen difüzyon yöntemi nötrozofik küme temelinde yeniden yorumlanmış ve nötrozofik küme bileşenlerini kullanan yeni bir difüzyon yöntemi geliştirilmiş̧ir. Önerilen yöntemin gradyan hesaplamasında orijinal giriş görüntüsü yerine görüntünün nötrozofik doğruluk kümesi kullanılmaktadır. Böylece gürültü etkileri azaltılmış bir türev bilgisi elde edilmiş̧ir. Ayrıca difüzyon işleminde kullanılan eğrilik hesaplamasında nötrozofik yanlışlık kümesi kullanılarak özellikle kenar bölgeleri boyunca arka plandan daha az etkilenen bir eğrilik bilgisi elde edilmiştir. Hesaplanan gradyan ve eğrilik bilgisi ters yayınım fonksiyonunun etkinliğini arttırarak iteratif difüzyon işleminin iyileştirici etkisini güçlendirmiştir. Renkli görüntülerde iyileştirme yapılırken görüntünün nötrozofik doğruluk kümesi YUV renk uzayına dönüştürülmüsşür. Doğruluk kümesinin sadece $Y$ bandı üzerinde difüzyon işlemi yürütülmüştür. Elde edilen iyileştirilmiş $\mathrm{Y}$ bandı daha sonra U ve V uzayı ile birleştirilerek tekrar RGB uzayına dönüştürülmüş ve iyileştirilmiş görüntü elde edilmiştir. Özellikle kenar bilgilerini koruma odaklı yapılan iyileştirme sonucunda önerilen yöntem diğer yöntemlerden daha iyi sonuçlar üretmiştir. Farklı gri seviye ve renkli görüntüler üzerinde yapılan deneysel çalışmalarda hem görsel açıdan hem de ortalama karesel hata açısından daha iyi sonuçlar elde edilmiş̧ir. Geliştirilen yöntem sınıflandırma, bölütleme ve arka plan ayırma gibi ileri işlemler öncesinde görüntülerdeki örtüşme problemini azaltmak için ön işlem olarak kullanılabilir. Bununla birlikte nötrozofik kümedeki filtre parametresi sonuçlar üzerinde etkili olmakla beraber yöntemin parametre bağımlılı̆̆ını arttırmaktadır. Ayrıca difüzyon işlemi öncesinde görüntü nötrozofik alana dönüştürüldüğ̈̈ için, Z-H yöntemine göre kısmen zaman maliyeti içermektedir.

\section{Kaynakça}

Abdallah, A., \& Zineb, A. (2018). Adaptive Non-linear Diffusion Based Local Binary Pattern for Image Denoising. In Proceedings of the 2018 International Conference on Applied Smart Systems, ICASS 2018, 1-5.

Casciola, G., Montefusco, L. B., \& Morigi, S. (2010). Edge-driven image interpolation using adaptive anisotropic radial basis functions. Journal of Mathematical Imaging and Vision, 36(2), 125-139.

Chae, E., Lee, E., Kang, W., Lim, Y., Jung, J., Kim, T., ... Paik, J. (2013). Frequency-domain analysis of discrete wavelet transform coefficients and their adaptive shrinkage for anti-aliasing. In 2013 IEEE International Conference on Image Processing, ICIP 2013 - Proceedings,1071-1074.

Gan, J., \& Taubman, D. (2007). Non-separable wavelet-like lifting structure for image and video compression with aliasing suppression. In IEEE International Conference in Image Processing, 65-68.

Jia, J., Barnard, K. J., \& Hirakawa, K. (2016). Fourier Spectral Filter Array for Optimal Multispectral Imaging. IEEE Transactions on Image Processing, 25(4), 1530-1543.

Jiang, X., Chen, X., He, L., \& Jeon, G. (2015). Improved directional weighted interpolation method combination with anti-aliasing FIR filter. In IST 2015 - 2015 IEEE International Conference on Imaging Systems and Techniques, Proceedings, 1-6.

Jidesh, P., \& George, S. (2012). Shock coupled fourth-order diffusion for image enhancement. Computers and Electrical Engineering, $38(5), 1262-1277$.

Kawase, M., Shinoda, K., \& Hasegawa, M. (2019). Demosaicking using a spatial reference image for an anti-aliasing multispectral filter array. IEEE Transactions on Image Processing, 28(10), 4984-4996.

Khan, T. M., Khan, M. A. U., \& Kong, Y. (2014). Fingerprint image enhancement using multi-scale DDFB based diffusion filters and modified Hong filters. Optik, 125(16), 4206-4214.

Kulberg, N. S., \& Yakovleva, T. V. (2012). Isotropic kernels for two-dimensional image interpolation. Journal of Mathematical Imaging and Vision, 44(3), 399-410.

Li, B., \& Meng, M. Q. H. (2012). Wireless capsule endoscopy images enhancement via adaptive contrast diffusion. Journal of Visual 
Communication and Image Representation, 23(1), 222-228.

Liu, C., Yan, X., \& Yang, B. (2017). An adaptive anisotropic thermal diffusion filter for image smoothing. In Proceedings - 2017 10th International Congress on Image and Signal Processing, BioMedical Engineering and Informatics, 1-5.

Mohan, J., Krishnaveni, V., \& Guo, Y. (2013). MRI denoising using nonlocal neutrosophic set approach of Wiener filtering. Biomedical Signal Processing and Control, 8(6), 779-791.

Nadernejad, E., Koohi, H., \& Hassanpour, H. (2008). PDEs-Based Method for Image Enhancement. Applied Mathematical Sciences, 2(20), 981-993.

Perona, P., \& Malik, J. (1990). Scale-Space and Edge Detection Using Anisotropic Diffusion. IEEE Transactions on Pattern Analysis and Machine Intelligence, 12(7), 629-639.

Smarandache, F., Broumi, S., Singh, P. K., Liu, C., Venkateswara Rao, V., Yang, H.-L., ... Elhassouny, A. (2019). Introduction to neutrosophy and neutrosophic environment. In Neutrosophic Set in Medical Image Analysis,3-29.

Smarandache, \& Florentin. (2003). A Unifying Field in Logics Neutrosophic Logic. Neutrosophy, Neutrosophic Set, Neutrosophic Probability (third). American Research Press.

Sung, M., \& Choi, S. (2017). Selective Anti-Aliasing for Virtual Reality Based on Saliency Map. In Proceedings - 2017 International Symposium on Ubiquitous Virtual Reality, 16-19.

Wang, Z., \& Qi, F. (2005). Analysis of multiframe super-resolution reconstruction for image anti-aliasing and deblurring. Image and Vision Computing, 23(4), 393-404.

Winger, L. L. (1999). Low-aliasing wavelets for pyramidal image coding. In IEEE International Conference on Image Processing Vol. $2,255-259$.

Yang, H., Gao, J., \& Wu, Z. (2007). An efficient approach for registration and super-resolution of aliased images. In 2007 International Symposium on Intelligent Signal Processing and Communications Systems, ISPACS 2007 - Proceedings,694-697.

Yang, L., Pedro V., S., Jason, L., \& Hugues, H. (2011). Antialiasing recovery. ACM Transactions on Graphics, 30(3), 1-9.

Yang, Y., Liu, F., Jin, Z., \& Crozier, S. (2015). Aliasing Artefact Suppression in Compressed Sensing MRI for Random Phase-Encode Undersampling. IEEE Transactions on Biomedical Engineering, 62(9), 2215-2223.

Zhao, C., Shao, M., Carass, A., Li, H., Dewey, B. E., Ellingsen, L. M., ... Prince, J. L. (2019). Applications of a deep learning method for anti-aliasing and super-resolution in MRI. Magnetic Resonance Imaging, 64, 132-141.

Zhao, Y., Xu, J., Li, H., \& Zhang, P. (2018). Edge information diffusion-based reconstruction for cone beam computed laminography. IEEE Transactions on Image Processing, 27(9), 4663-4675.

Ziou, D., \& Horé, A. (2011). Reducing aliasing in images: A simple diffusion equation based on the inverse diffusivity. In Proceedings - International Conference on Image Processing, 3389-3392.

Ziou, D., \& Horé, A. (2012). Reducing aliasing in images: A PDE-based diffusion revisited. Pattern Recognition, 45(3), $1180-1194$. 